\title{
Simulation of calcium acetylide and acetylene production
}

\author{
Igor Oršula, Miroslav Lehocký, Pavol Steltenpohl \\ Institute of Chemical and Environmental Engineering, Faculty of Chemical and Food Technology, \\ Slovak University of Technology in Bratislava, Radlinského 9, 81237 Bratislava, Slovakia \\ pavol.steltenpohl@stuba.sk
}

Presented at the $3^{\text {rd }}$ International Conference on Chemical Technology, April 13-15, 2015,

Mikulov, Czech Republic: Czech Society of Industrial Chemistry

\begin{abstract}
Design simulation of a reactor for acetylene production from calcium acetylide and its purification in the gaseous phase is presented. Simulations were performed using the program ASPEN+ which is a very flexible and useful tool for the simulation and optimization of various types of chemical technologies including gas-liquid-solid systems. The first step of the acetylene synthesis, based on coal as the raw material, is the production of calcium acetylide. This substance is obtained from coke and limestone in an electric arc furnace at elevated temperatures. Raw materials used in this process contain relatively large amounts of impurities that are converted and entrapped in the desired product of the above reaction. Some of the impurities, e.g. metallic iron or its alloys, can be separated easily. However, most of the other elements present in the form of their compounds with calcium remain a part of "technical grade" calcium acetylide. Acetylene is commercially produced by the reaction of "technical grade" calcium acetylide with water under controlled reaction conditions in an inert atmosphere. Depending on the purity of calcium acetylide used, the produced raw acetylene contains a variety of admixtures that lower its quality. As a consequence, prior to its expedition to the customer, raw acetylene should be submitted to a down-stream processing that consists of the separation of basic and acidic pollutants present in acetylene by absorption. The final processing step is adsorption and/or freezing-out of water vapor from the purified acetylene stream. Besides acetylene, the reaction of calcium acetylide with an excess of water provides aqueous calcium hydroxide. In order to commercialize this byproduct, the content of water in the mixture should be lowered to the required level. In this contribution, development of a model of calcium acetylide and acetylene production as well as the simulation of these processes in ASPEN + are presented. Simulation results of a realistic production line model correlate very well with the actual data from the technology used in Fortischem, a.s., Nováky, Slovakia.
\end{abstract}

Keywords: calcium acetylide, acetylene, equipment simulation, down-stream processing

\section{Introduction}

Acetylene is a gaseous hydrocarbon composed of 92.2 mass \% of carbon and 7.8 mass \% of hydrogen and it is approximately by $10 \%$ lighter than air. Acetylene possesses characteristics that make it suitable as a chemical intermediate and for technical applications. It is a starting material for synthesizing many organic substances including 1,4-butanediol, vinyl chloride, other vinyl compounds (acrylonitrile, etc.), polymers, surface active agents, and many others. Acetylene shows high calorific value due to the special combination of carbon and hydrogen atoms composing its molecule. This fact is employed in acetylene welding and cutting of metals. On the other hand, manipulation with acetylene is risky due to its elevated explosiveness and storage exigencies (Miller, 1965a; Tribolet, 2005). In 1896, the French scientists Claude and Hess discovered a way to store and transport acetylene without the risk of explosion. This method is based on the fact that acetylene readily dissolves in acetone. The French call acetylene dissolved in acetone acétylène-dissous. At the pressure of $1 \mathrm{MPa}$, one liter of acetone dissolves in approximately 250 liters of acetylene. However, the amount of acetylene absorbed by acetone is quickly reduced due to the presence of impurities, e.g. phosphorus or arsenic compounds (Fortischem, 2014a; Bránsky, 1958).

Acetylene is produced from fossil raw materials: by partial combustion of natural gas, by hydrocarbons cracking of crude, and by the reaction of calcium acetylide with water from coal. At present, acetylene is almost exclusively produced from natural gas and naphtha, the major raw materials consumed across the world. However, it becomes increasingly apparent that their reserves are limited. If the increase of oil and gas consumption continues, their known reserves will be depleted in a few decades. In contrast, coal reserves are sufficient for several hundreds of years, especially those of lignite, which are estimated for 227 years (Diercks et al., 2008). Thus, coal-based production of chemicals can lower the World's dependence on oil. 
In a large scale, hydrocarbons with a low number of carbon atoms in the molecule can be produced from coal using two procedures. The first involves methanol production via coal gasification. Methanol produced in this way is converted to olefins by the methanol-to-olefin technique. The other method is acetylene production from water and calcium acetylide obtained by the reaction of coal with lime (Miller, 1965b).

Calcium acetylide, an intermediate product of the coal-to-calcium acetylide-to-acetylene process, was once named the mother of organic synthesis. Moreover, in the calcium acetylide production from coal, also other valuable product is obtained. The content (purity) of carbon monoxide in the off-gas emitted during calcium acetylide production is very high, exceeding the CO content in the synthesis gas obtained by coal gasification (Miller, 1965b).

In the electro-thermal calcium acetylide manufacturing process (ETMP), high-quality cokes produced by coking high-rank coal are required. In ETMP, electricity is converted to thermal energy employing an electric arc furnace so that coke reacts with quick lime at ca. $2000{ }^{\circ} \mathrm{C}$ to produce calcium acetylide and carbon monoxide. ETMP was already used in an industrial scale $\mathrm{CaC}_{2}$ production in the early 1960s (American Chemical Society, 1998). However, disadvantages of this technology, such as high energy consumption and environmental pollution, slowed down its development. Calcium acetylide production via ETMP is characterized by high energy consumption (ca. $3500 \mathrm{kWh}$ per t of calcium acetylide) required to reach the extreme reaction conditions required (Fortischem, 2014b).

The process of acetylene production from calcium acetylide, i.e. the reaction of calcium acetylide with water, was developed in 1862 by Wöhler. In this wet production of acetylene, excess of water is used. A part of water introduced into the reactor is converted while the excess amount of water quenches the reaction mixture thus limiting the risk of explosion caused by overheating due to the large amount of heat produced by the reaction. An important parameter in the production of acetylene is its purity. Raw acetylene produced from coal contains several admixtures such as $\mathrm{PH}_{3}, \mathrm{H}_{2} \mathrm{~S}, \mathrm{NH}_{3}$, and $\mathrm{AsH}_{3}$ that reduce its quality. These substances should be eliminated from acetylene by absorption with aqueous sulfuric acid or sodium hypochlorite solutions. The final step in acetylene purification is the elimination of water vapor by adsorption and/or freeze-drying (Fortischem, 2014a; Miller, 1965b).

The aim of this study is the design and simulation of acetylene production from coal (coke) taking into account all constraints and requirements posted on this process in a real factory (Fortischem, a.s., Nováky, Slovakia). Firstly, the designed production line was modeled (Večeř, 2013; Fogler \& Gurmen, 2002) using the simulation engine ASPEN+. The developed model was tuned to fit realistic data from the existing plant. This model can also serve as a basis for the optimization of the plant operational costs and design of alternative solutions of individual equipments.

\section{Design and simulation of acetylene production from coal}

\section{Calcium acetylide production}

The molecule of calcium acetylide consists of two carbon atoms and one calcium atom; it melts at about $1926{ }^{\circ} \mathrm{C}$. Commercially produced "technical grade" calcium acetylide is a gray to black solid that is typically supplied as granules. It contains about 75 mass \% to 85 mass \% of calcium acetylide with 25 mass \% to 15 mass \% of calcium oxide and other impurities. Liquid $\mathrm{CaC}_{2}$ is produced by the electrothermal manufacturing process (ETMP) in an electric arc furnace, where the raw material (coke and lime) is heated to reaction temperatures above $2000{ }^{\circ} \mathrm{C}$ by electricity. As flammable byproduct, carbon monoxide is evolved according to the reaction:

$$
\mathrm{CaO}+3 \mathrm{C} \stackrel{\Delta}{\longrightarrow} \mathrm{CaC}_{2}+\mathrm{CO}
$$

Since coke contains a small amount of hydrogen, also extremely flammable hydrogen gas $\left(\mathrm{H}_{2}\right)$ is released during the process.

As shown in Fig. 1, ETMP can be divided into two subsystems: the calcium acetylide manufacturing process and a subsystem of utilities. The subsystem of the calcium acetylide manufacturing consists of an electric arc (carbide) furnace and a separator of solids wafted by the off-gas from the reactor. Coke with anthracite, lime, and electrode paste are introduced into the acetylide furnace. Electrode paste ensures heating of the raw material by electricity. All feedstock is heated to $2000{ }^{\circ} \mathrm{C}$ by electricity at the constant pressure of $0.10 \mathrm{MPa}$. Under these conditions, CO-gas and calcium acetylide are produced according to the stoichiometric equation (Eq. (1)). The carbon monoxide-rich gas phase continuously leaves the acetylide furnace containing fine dust of coke and lime which is removed from the gas-phase in a cyclone separator. Purified CO-gas can be further used, e.g. to improve the energy balance of the plant. The electric arc furnace is operated discontinuously. After completing the reaction, the calcium acetylide melt is tapped out of the furnace, collected, and allowed to cool down prior to further manipulation. Representative amounts and compositions of individual streams are presented in Table 1. 


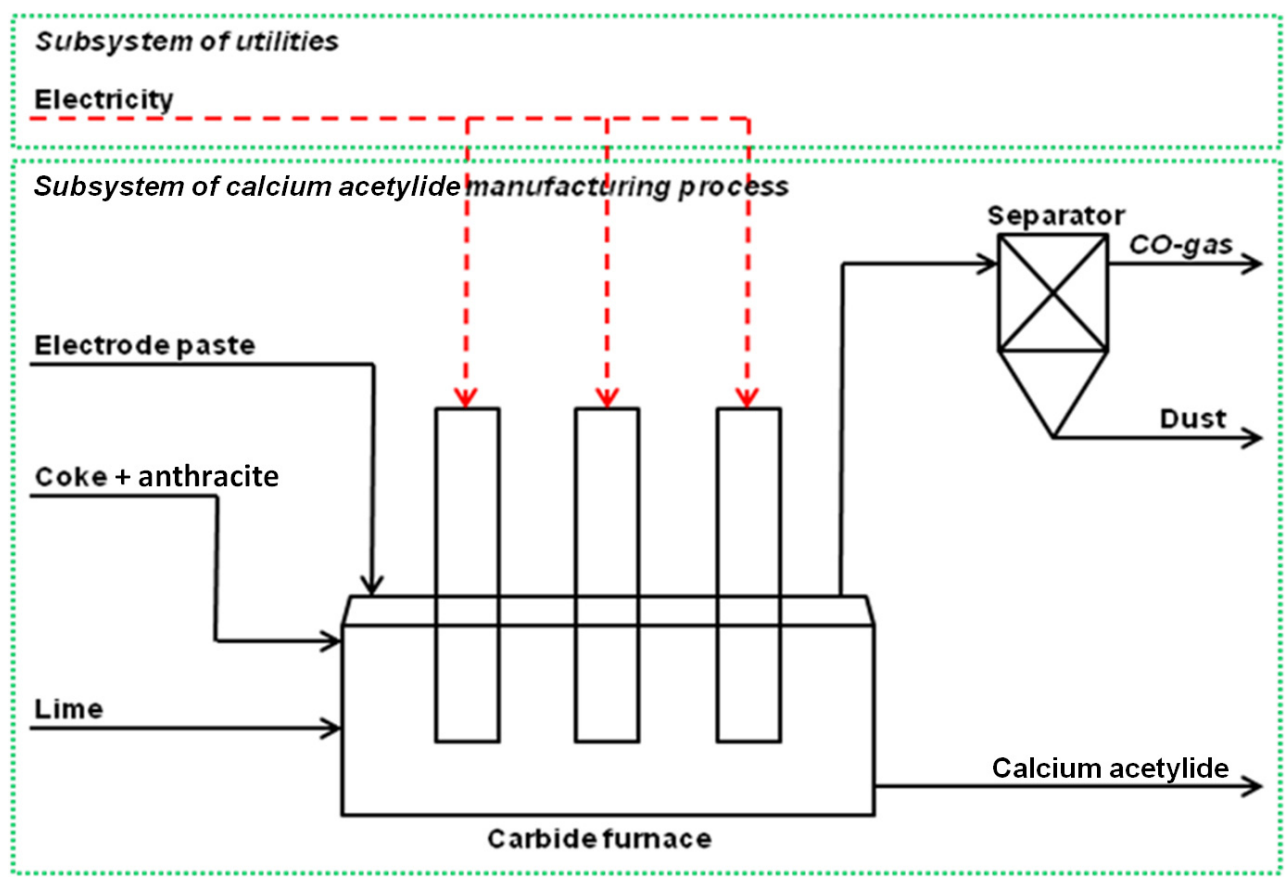

Fig. 1. Scheme of the coal-based calcium acetylide electro-thermal manufacturing process (ETMP) in an electric arc (carbide) furnace.

Tab. 1. Stream composition and typical conditions of the calcium acetylide manufacturing process.

\begin{tabular}{|c|c|c|c|c|c|c|c|}
\hline & Coke $^{a}$ & Anthracite $^{a}$ & Lime $^{a}$ & Electrode paste $^{a}$ & CO-gas & Dust & Calcium acetylide \\
\hline$t\left({ }^{\circ} \mathrm{C}\right)$ & 20 & 20 & 20 & 20 & 600 & 20 & 2000 \\
\hline$P(\mathrm{kPa})$ & 100 & 100 & 100 & 100 & 100 & 100 & 100 \\
\hline Component & & & & Mass fraction & & & \\
\hline $\mathrm{H}_{2} \mathrm{O}$ & 0.0091 & 0.0019 & 0 & 0 & 0 & 0 & 0 \\
\hline C & 0.9029 & 0.9717 & 0 & 0.9568 & 0 & 0.1398 & 0 \\
\hline $\mathrm{SiO}_{2}$ & 0.0009 & 0 & 0.0019 & 0 & 0 & 0.0112 & 0.0009 \\
\hline $\mathrm{Al}_{2} \mathrm{O}_{3}$ & 0.0006 & 0 & 0.0010 & 0 & 0 & 0.0065 & 0.0007 \\
\hline $\mathrm{Fe}_{2} \mathrm{O}_{3}$ & 0.0004 & 0 & 0.0007 & 0 & 0 & 0.0046 & 0 \\
\hline $\mathrm{MgO}$ & 0 & 0 & 0.0060 & 0 & 0 & 0.0398 & 0.0025 \\
\hline S & 0.0036 & 0.0034 & 0 & 0 & 0 & 0.0081 & 0 \\
\hline $\mathrm{P}_{2} \mathrm{O}_{5}$ & 0.0002 & 0.0001 & 0 & 0 & 0 & 0 & 0 \\
\hline $\mathrm{CaO}$ & 0 & 0 & 0.9494 & 0 & 0 & 0.4110 & 0.1656 \\
\hline $\mathrm{CaCO}_{3}$ & 0 & 0 & 0.0409 & 0 & 0 & 0 & 0 \\
\hline $\mathrm{CO}$ & 0 & 0 & 0 & 0 & 0.9989 & 0 & 0 \\
\hline $\mathrm{CO}_{2}$ & 0 & 0 & 0 & 0 & trace & 0 & 0 \\
\hline $\mathrm{H}_{2}$ & 0 & 0 & 0 & 0 & 0.0011 & 0 & 0 \\
\hline $\mathrm{CH}_{4}$ & 0 & 0 & 0 & 0 & trace & 0 & 0 \\
\hline $\mathrm{SO}_{2}$ & 0 & 0 & 0 & 0 & trace & 0 & 0 \\
\hline $\mathrm{CaC}_{2}$ & 0 & 0 & 0 & 0 & 0 & 0 & 0.8221 \\
\hline $\mathrm{Ca}_{3} \mathrm{P}_{2}$ & 0 & 0 & 0 & 0 & 0 & 0 & 0.0001 \\
\hline $\mathrm{CaS}$ & 0 & 0 & 0 & 0 & 0 & 0 & 0.0026 \\
\hline $\mathrm{FeSi}$ & 0 & 0 & 0 & 0 & 0 & 0 & 0.0005 \\
\hline Ash & 0.0823 & 0.0229 & 0 & 0.0432 & 0 & 0.3790 & 0.0050 \\
\hline
\end{tabular}

a) Data correspond to the supplier specifications on the raw material compositions. 
The subsystem of utilities provides electric power for the acetylide furnace heating and drives the separator during calcium acetylide production (Fortischem, 2014b).

\section{Production and purification of acetylene}

Acetylene is generated by the reaction of calcium acetylide with water according to the following equation:

$$
\mathrm{CaC}_{2}+2 \mathrm{H}_{2} \mathrm{O} \longrightarrow \mathrm{C}_{2} \mathrm{H}_{2}+\mathrm{Ca}(\mathrm{OH})_{2}
$$

Many types of devices have been used over the years to provide acetylene from calcium acetylide, which are commonly called generators. Fig. 2 shows a calcium acetylide wet generator used nowadays.

Depending on the reaction conditions, the design of an acetylene generator is varied. Probably the most important parameter influencing both the reaction conditions and the reactor design is the water consumption. Basically, two types of acetylene generators are distinguished. Dry lime generators use barely one liter of water per kilogram of acetylide, so lime is formed as a powder. Such generators generally work at a temperature close to $100{ }^{\circ} \mathrm{C}$. On the other hand, wet generators use $6-10$ liters of water per kilogram of calcium acetylide, i.e. a large surplus of water in relation to the amount involved in the reaction. Then, lime slurry is formed as a byproduct in the reactor. In the present study, a wet acetylene generator was considered in line with the real plant operated in Fortischem, a.s., Nováky, Slovakia.

Besides the principal reaction (acetylene formation), also reactions of contaminants, remnants

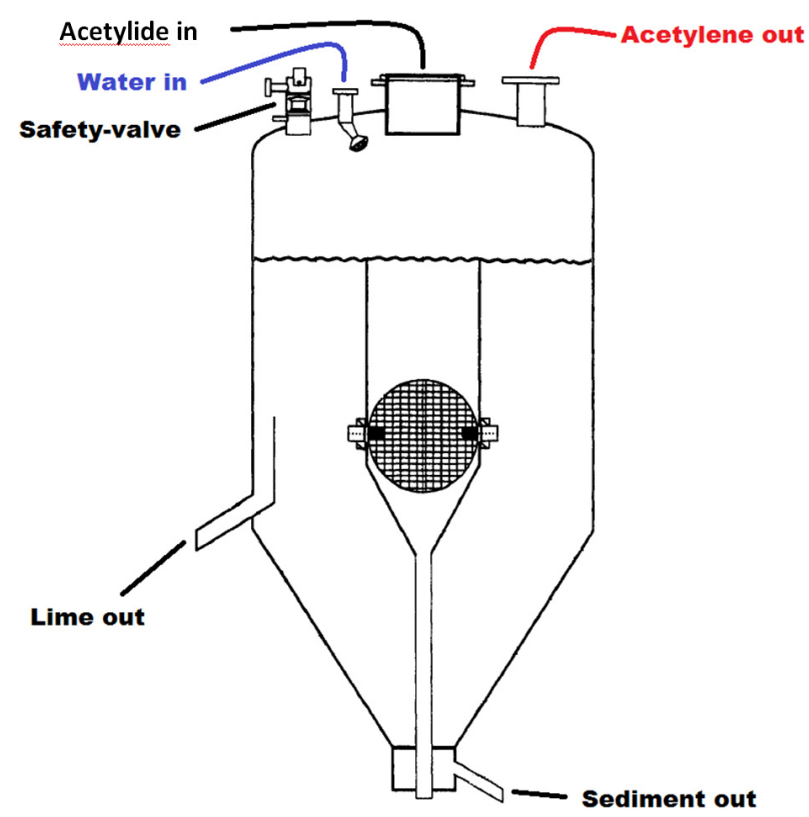

Fig. 2. Wet generator for the acetylene production from calcium acetylide.

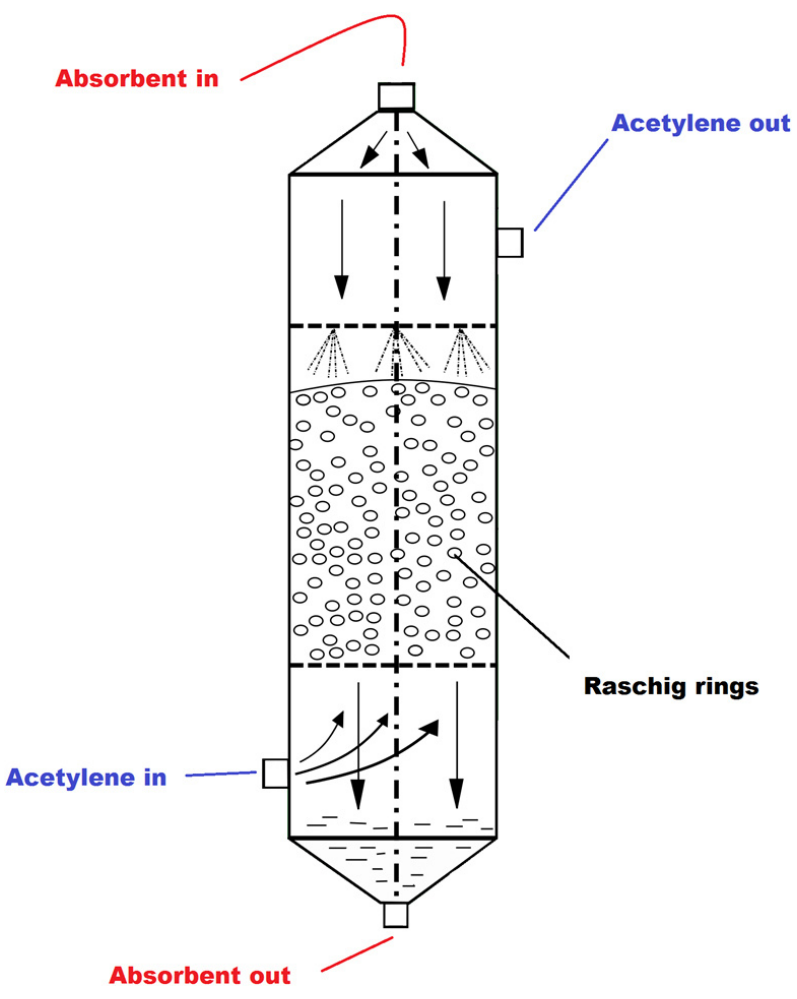

Fig. 3. Absorption column for the removal of impurities from acetylene.

of admixtures in coke and lime from the calcium acetylide production with water take place in the generator. Consequently, impurities such as ammonia, hydrogen sulfide, phosphine, and arsine are formed. These pollutants should be removed from raw acetylene in order to meet the quality requirements. Separation is carried out in absorption columns (Fig. 3), where $\mathrm{NH}_{3}, \mathrm{H}_{2} \mathrm{~S}, \mathrm{PH}_{3}$, and $\mathrm{AsH}_{3}$ are reacted/oxidized to form non-volatile compounds soluble in water. In Fortischem, a.s., Nováky, Slovakia, absorption is carried out by contacting raw acetylene with a solution of sodium hypochlorite. The next step of acetylene purification is the absorption of acidic pollutants, mainly $\mathrm{SO}_{2}$ and $\mathrm{Cl}_{2}$, formed during the reactive absorption of the above impurities in the aqueous sodium hypochlorite solution. Due to the contact with the aqueous phase in the absorption columns, acetylene is saturated with water vapor removed by contacting this stream with brine in the brine cooler. In order to minimize the water vapor content, acetylene can be further cooled down or contacted with adsorbent. Purified gas is shipped to the end users. In Fortischem, a.s., Nováky, Slovakia, these are the divisions Dissous plyn, Chémia, and Plasty.

Flow sheet of the acetylene production and purification plant is given in Fig. 4 showing the principal equipment involved in this production line. Simulation was carried out taking into account the average 

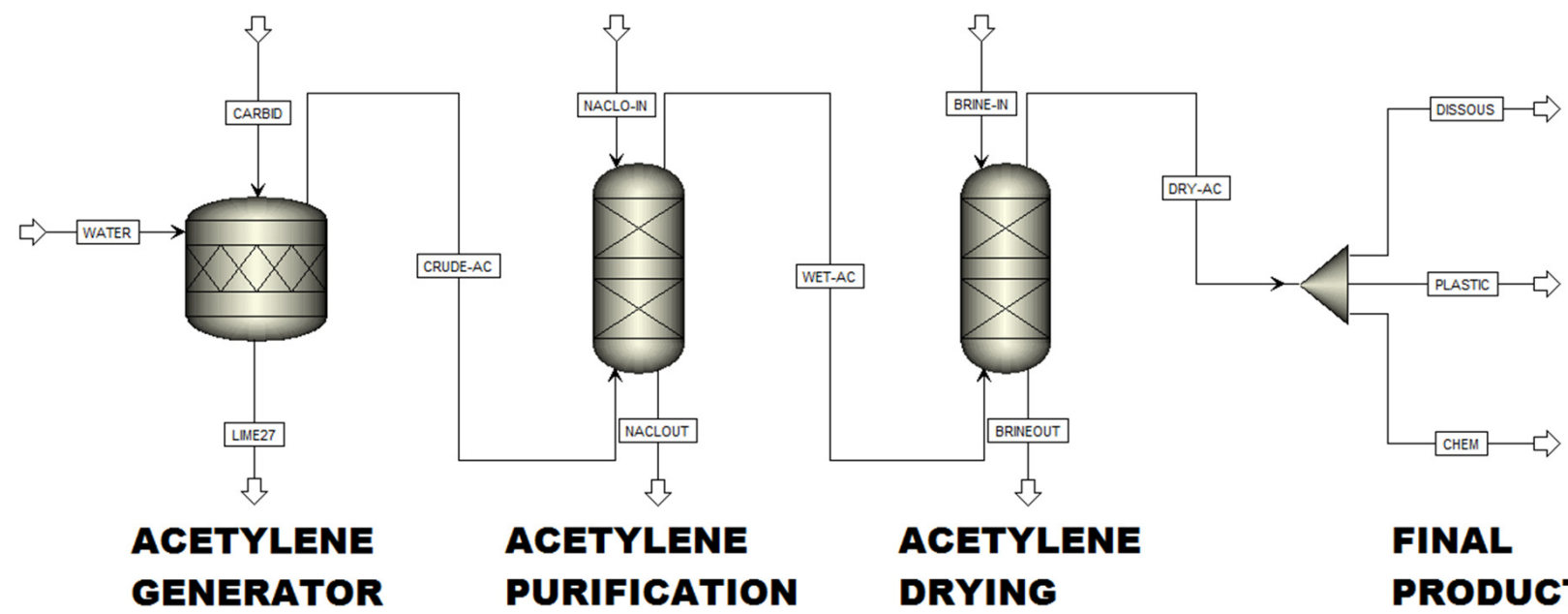

Fig. 4. Flow sheet of acetylene production and purification plant in ASPEN+.

Tab. 2. Stream composition and typical conditions of acetylene production and purification process (for the stream abbreviations, see Fig. 4).

\begin{tabular}{|c|c|c|c|c|c|c|c|c|}
\hline & Water & Acetylide & Lime27 & Crude-Ac & Wet-Ac & Dissous & Plasty & Chémia \\
\hline$t\left({ }^{\circ} \mathrm{C}\right)$ & 25 & 15 & 36 & 26 & 20 & 7 & -18 & -18 \\
\hline$P(\mathrm{kPa})$ & 101.33 & 101.33 & 101.33 & 105.50 & 105.50 & 152 & 152 & 152 \\
\hline Component & \multicolumn{8}{|c|}{ Mass fraction } \\
\hline $\mathrm{CaC}_{2}$ & 0 & 0.8221 & 0 & 0 & 0 & 0 & 0 & 0 \\
\hline $\mathrm{H}_{2} \mathrm{O}$ & 1 & 0 & 0.7380 & 0.0132 & 0.0112 & trace & trace & trace \\
\hline $\mathrm{C}_{2} \mathrm{H}_{2}$ & 0 & 0 & 0 & 0.9856 & 0.9888 & 1 & 1 & 1 \\
\hline $\mathrm{Ca}(\mathrm{OH})_{2}$ & 0 & 0 & 0.2620 & 0 & 0 & 0 & 0 & 0 \\
\hline $\mathrm{CaO}$ & 0 & 0.1656 & 0 & 0 & 0 & 0 & 0 & 0 \\
\hline $\mathrm{CaS}$ & 0 & 0.0026 & trace & 0 & 0 & 0 & 0 & 0 \\
\hline $\mathrm{H}_{2} \mathrm{~S}$ & 0 & 0 & 0 & 0.0004 & trace & trace & trace & trace \\
\hline $\mathrm{Ca}_{3} \mathrm{P}_{2}$ & 0 & 0.0001 & trace & 0 & 0 & 0 & 0 & 0 \\
\hline $\mathrm{PH}_{3}$ & 0 & 0 & 0 & 0.0004 & trace & trace & trace & trace \\
\hline $\mathrm{AsH}_{3}$ & 0 & 0 & 0 & trace & trace & 0 & trace & trace \\
\hline $\mathrm{Ca}_{3} \mathrm{~N}_{2}$ & 0 & trace & trace & 0 & 0 & 0 & 0 & 0 \\
\hline $\mathrm{NH}_{3}$ & 0 & 0 & 0 & 0.0004 & trace & 0 & 0 & 0 \\
\hline $\mathrm{H}_{2} \mathrm{SO}_{4}$ & 0 & 0 & 0 & 0 & trace & 0 & 0 & 0 \\
\hline $\mathrm{H}_{3} \mathrm{PO}_{4}$ & 0 & 0 & 0 & 0 & trace & 0 & 0 & 0 \\
\hline $\mathrm{H}_{3} \mathrm{ASO}_{4}$ & 0 & 0 & 0 & 0 & trace & 0 & 0 & 0 \\
\hline $\mathrm{NaOH}$ & 0 & 0 & 0 & 0 & trace & 0 & 0 & 0 \\
\hline C & 0 & 0.0050 & 0 & 0 & 0 & 0 & 0 & 0 \\
\hline
\end{tabular}

Tab. 3. Conformity of simulation in ASPEN+ with real production.

\begin{tabular}{lccc}
\hline \multirow{2}{*}{ Division } & \multicolumn{3}{c}{ Mass flow (a.u.) } \\
\cline { 2 - 4 } & Computed by Aspen+ & Real production & Difference \\
\hline Dissous plyn & 17.8 & 17.8 & 0 \\
Chémia & 55.1 & 55.1 & 0 \\
Plasty & 931.8 & 927.1 & +4.7 \\
\hline Total & 1004.7 & 1000.0 & +4.7 \\
\hline
\end{tabular}


annual acetylene production in Fortischem, a.s., Nováky, Slovakia. Table 2 presents the results of calculation of stream compositions obtained by ASPEN+. Based on the changes of the pollutants and water vapor contents in individual acetylene streams, one can observe the progress of acetylene purification and drying.

Table 3 shows comparison of simulation results with acetylene production data. Comparison is based on the computed and measured (arbitrary) amounts of acetylene supplied to the three divisions of the factory Fortischem, a.s., Nováky, Slovakia.

\section{Conclusions}

In this study, a realistic model of an acetylene production plant was composed in the ASPEN+ simulation engine (Figs. 1 and 4). The electric arc (carbide) furnace and acetylene generator were simulated using the Gibbs reactor approach. Besides the reactive absorption columns for the conversion of impurities present in raw acetylene, several other separation equipments, such as a cyclone separator, Door's centrifuge, absorption columns, etc., were included in the developed model. Results of the simulation correlate very well (Table 3) with the data from a real production plant in the factory Fortischem, a.s., Nováky, Slovakia.

The developed model can be applied not only for the optimization of the existing production plant but it is a good starting point for suggesting alternative solutions for individual equipments involved.

\section{Acknowledgement}

The authors acknowledge the Research and Development Assistance Agency APVV (APVV-0858-12) for financial support.

\section{References}

American Chemical Society (1998) Discovery of the commercial processes for making calcium carbide and acetylene. ACS, Washington, DC, USA.

Bránsky E (1958) Acetylén. Polygrafické závody, Bratislava, Slovakia.

Diercks R, Arndt JD, Freyer S, Geier R, Machhammer O, Schwartze, J, Volland M (2008) Chemical Engineering \& Technology 31: 631-637. DOI: 10.1002/ceat.200800061.

Fogler HS, Gurmen NM (2002) Aspen Plus Workshop for Reaction Enginnering and Desing, The University of Michigan, Ann Arbor, MI, USA.

Fortischem (2014a) The technological regulation: Purification of acetylene production. Fortischem, a.s., Nováky, Nováky, Slovakia.

Fortischem (2014b) The technological regulation: Calcium carbide production. Fortischem, a.s., Nováky, Nováky, Slovakia.

Miller SA (1965a) History of Acetylene Industry. British Oxygen Co., Guildford, UK.

Miller SA (1965b) Acetylene: Its Properties, Manufacture, and Uses (11 ${ }^{\text {th }}$ ed.). Academic Press, New York, NY, USA.

Tribolet RO (2005) The History of Acetylene Industry. Union Carbide, Houston, TX, USA.

Večeř M (2013) Úvod do modelováni chemicko-technologických procesů. Technical University Ostrava, Ostrava, Czech Republic. 